JOURNAL OF BIOMEDICAL RESEARCH \& CLINICAL

PRACTICE

\title{
Correlates of HIV Risky Sexual Behaviours in an Era of Antiretroviral Therapy Scale-Up: A Cross-Sectional Study among the Adult General Population in Nasarawa State, Nigeria
}

Bako IA, ${ }^{1 *}$ Anyanti JO, ${ }^{2}$ Roca-Feltrer A. ${ }^{3}$

${ }^{I}$ College of Health Sciences, Benue State University, Makurdi, Nigeria

${ }^{2}$ Society for Family Health, Abuja, Nigeria

${ }^{3}$ London School of Hygiene and Tropical Medicine, University of London, UK.

\section{ABSTRACT}

*Corresponding Author: Dr Ishaku Ara Bako, Department of Epidemiology and Community Health College of Health Sciences Benue State University, Makurdi, Nigeria. Email: bakoiara@yahoo.com

Analyses of HIV incidence in Nasarawa State Nigeria estimate that most of the new HIV infections occur among persons who reported low HIV risk including couples. The study was aimed at identifying the factors that predict risky sexual behavior among the general population in Nasarawa state, Nigeria. Data analysis was carried on a total of 801 respondents sampled from the general population of Nasarawa State, Nigeria. The original sample was obtained through a two-stage cluster sampling technique using probability proportionate to size. The primary outcome variable was risky sexual behavior. Chi-square and logistic regression analyses were used to determine the association between the outcome and selected Sociodemographic and other independent variables. Females were $54.2 \%$ of the total sampled population analysed, the mean age of the respondents was 29.8 years (SD: 10.3). About two-third of the respondents engaged in risky sexual behaviours (65.9\%) but only $4.7 \%$ considered themselves to be at high risk of HIV. The multivariable regression analysis showed that factors associated with risky sexual behaviour included : been male sex [OR: 0.63; 95\% CI: 0.436-0.915], married [OR: 0.26: 95\% CI: 0.163 - 0.419 ], rural resident [OR: 1.20 ; $95 \%$ CI: 0.775 to 1.871 ], age 20-24 [OR: 1.93, 95\% CI: 1.113 - 3.360] and 25-29 years [OR: 2.34; $95 \%$ CI: 1.267-1.308]; and knowledge of HIV [OR: 1.49; 95\% CI: 1.056-2.108].There is a need to urgently intensify media campaigns, community-based interventions including one on one communications to reduce risky sexual behaviours.

Keywords: Risk factors, Sexual behaviour, HIV.

$P_{c}$ ersons who engage in risky sexual behaviours are at risk of contracting HIV/AIDS and other sexually transmitted infections. The huge difference in the HIV prevalence between sub- Saharan Africa and developed countries has been partly attributed to differences in the prevalence of risky sexual behaviors, especially if such are done outside of stable/regular relationships. ${ }^{1}$ A study in Uganda showed that prevalence of HIV (33.4\% among men and women 50.2\%) was significantly associated with not using a condom during sex and having two or more sexual partners. ${ }^{2}$ Sexual behaviors of a people have been attributed, to some extent, to the moral and cultural values within the community. Accordingly, in communities where sexual permissiveness is less tolerated, risky sexual behaviors are less prevalent. ${ }^{3} \mathrm{With}$ increasing globalization and socioeconomic modernization, however, there is an increasing tendency for individuals to become more oriented towards 
autonomous decisions and hence more likelihood to break these societal and cultural inhibitions. ${ }^{4}$ However, cultural inhibitions could also prevent people from using preventive measures such as the inability of the female sexual partners to initiate condom use during sex. ${ }^{5}$

Reduction of risky sexual behavior' is a target of many HIV and STI interventions. However, HIV and STI epidemiology varies widely. Several studies have been conducted among adolescent and young persons' sexual behaviours, but not much has been done on risk taking behaviours at the general population level. Studies across Africa showed that sexual behaviour vary with different populations. Recent analysis of modes of HIV transmission in Africa and other developing countries have however suggested that the general population accounts for a significant proportion of new HIV infections. ${ }^{6,7,8 .}$ It has therefore been suggested that the epidemiology of HIV and other sexually transmitted infections vary, necessitating the need for local evidences to guide prevention interventions. ${ }^{9,10}$ It is imperative that we understand the predictors of risky sexual behavior among the general population in Nasarawa state. Understanding this would enable both policy makers and HIV prevention programme implementers to prioritize their interventions. This study was therefore aimed at determining the prevalence and factors that predict risky sexual behavior which consists of an aggregate of early sexual debut, transactional sex and multiple sexual partnering among the general population in Nasarawa state, Nigeria.

\subsection{MATERIALS AND METHODS}

\section{Study Design}

This cross-sectional analytical study was conducted in 2011 among the general population in Nasarawa State Nigeria.

\section{Study Population}

Persons eligible to participate in the study were females aged 15 - 49 years and males aged 15-64 years and living in Nasarawa State Nigeria. A sample size of 840 was determined using the appropriate formula and using Contraceptive Prevalence rate of $9.7 \%$ obtained from the National Demographic Health Survey Nigeria, 2008 and 2.5\% level of precision.

Probability sampling techniques was used through a two stage sampling. In stage one, 30 Enumeration Team Areas (ETA) were selected using the cumulative measure of size of the
Enumeration area in the state. The ETA were listed with their cumulative population sizes and selection was done using random numbers. In stage two, eligible individuals were randomly selected from a list within each cluster. The sample allocation to urban and rural areas was proportional to the rural/urban distribution of the population. A locality with a population of less than 20,000 was classified as a rural area. In this stage, the buildings and households within each selected ETA were identified and members of the households were listed with their names, ages and sexes. All eligible persons were identified and numbered serially. Systematic random sampling procedure was used to select 28 persons (14 males and 14 females) from each cluster.

\section{Study Procedures}

Each of the selected respondents was approached and given explanations about the study and then signed an informed consent form. A structured questionnaire was administered to selected individuals. Information was obtained on the background information of respondents, sexual behavior, knowledge and perception of HIV/AIDS, substance use, accessibility and use and access to HIV Counseling and Testing by trained interviewers. Risky sexual behavior was determined by finding the average score for the following (see table 2.1): early sexual initiation (Sexual debut before 15 years), transactional sex in past 12 months and number of sex partners in the past 12 months. Table 2.1 summarized the scoring for each of the variables.

The total score for each respondent were added up to get the total score. Total score of 3 and lower were labeled as having low risk while any respondent with a total score of 4 and above was considered to have a high risk sexual behaviour. The exposure variables include the following: sex, age, location, educational attainment, marital status, self-perception of risk of HIV transmission, alcohol and substance use and comprehensive knowledge of HIV.

\section{Data Analysis}

Data analysis was done using the STATA package. The level of significance for the analysis was 5\% and analysis was done using chi square, crude logistic regression and multivariable regression. 
Table 2.1: Scoring of the risky sexual behaviours variables

\begin{tabular}{|c|c|c|c|}
\hline Sn & Risky Sexual & Responses & Code \\
\hline 1. & Age at sexual initiation & $\begin{array}{l}\text { i. Never had sex } \\
\text { ii. }>\text { or }=18 \text { years } \\
\text { iii. } 16-17 \text { yeqrs } \\
\text { iv. } 15 \text { years or less }\end{array}$ & $\begin{array}{l}0 \\
1 \\
2 \\
3\end{array}$ \\
\hline 2. & $\begin{array}{l}\text { Number of sex } \\
\text { partners during the previous } \\
12 \text { months }\end{array}$ & $\begin{array}{l}\text { i. Never had sex } \\
\text { ii. } 1 \\
\text { iii. } 2 \text { or more }\end{array}$ & $\begin{array}{l}0 \\
1 \\
2\end{array}$ \\
\hline 3. & $\begin{array}{l}\text { Transactional sex in } \\
\text { the past } 12 \text { months }\end{array}$ & $\begin{array}{l}\text { i. Never have sex in past } \\
12 \text { months } \\
\text { ii. No } \\
\text { iii. Yes }\end{array}$ & $\begin{array}{l}0 \\
1 \\
2\end{array}$ \\
\hline
\end{tabular}

\section{Ethical Consideration}

Permission to carry out secondary data analysis was obtained from Society for Family Health (SFH) Nigeria while ethical approval for the original data collection was earlier obtained from the National Health Research Ethics committee of Nigeria (NHREC). The data do not have identifiers, so confidentiality of population that was used for the original data is maintained.

\section{RESULTS}

\subsection{Socio-Demographic Characteristics}

Table 3.1 shows the respondents' socio-demographic characteristics. Majority of them were females (54.2\%) and aged 25-64 years) $65.8 \%$ ). The mean age was 29.83 ( \pm 10.3 ) years, the youngest respondent was 15 years while the oldest was 64 years. The majority of the respondents were ever married $(70.7 \%)$, while $(29.3 \%)$ were never married. Rural residents form the majority of the respondents (83\%). Slightly more than a third (35\%) never attended school and only $11.2 \%$ had tertiary level education. (Table 3.1)

\subsection{Sexual behaviours and other selected characteristics}

Majority of the respondents, $489(61.1 \%)$ had their first sex at age 18 years or older while $188(23.5 \%)$ had their sexual debut at 15 years or younger. Only $51(6.4 \%)$ had transactional sex in the previous 12 months and $189(23.6 \%)$ had two or more sexual partners in the previous year. Majority had no comprehensive knowledge of HIV (57.8\%), ever done HIV test (55.7 \%) and had a low self-risk perception of HIV (85.1\%). Regular alcohol use and substance use were reported by $9.7 \%$ and $5.9 \%$ of the respondents respectively. (Table 3.2)
Table 3.1: Distribution of general population by Sociodemographic characteristics Nasarawa State, Nigeria, 2014

\begin{tabular}{|c|c|c|c|}
\hline & Variable & $\mathrm{n}$ & $\%$ \\
\hline \multirow[t]{3}{*}{1.} & Sex of respondents & & \\
\hline & $\checkmark \quad$ Male & 367 & 45.8 \\
\hline & $\checkmark$ Female & 434 & 54.2 \\
\hline \multirow[t]{4}{*}{2.} & Age groups (years) & & \\
\hline & & 274 & 34.2 \\
\hline & & 527 & 65.8 \\
\hline & $\checkmark \quad$ Mean Age (SD) (years) & $29.83(10.3)$ & \\
\hline \multirow[t]{3}{*}{3.} & Marital Status & & \\
\hline & $\checkmark \quad$ Ever Married & 566 & 70.7 \\
\hline & $\checkmark \quad$ Never married & 235 & 29.3 \\
\hline \multirow[t]{3}{*}{4.} & Location & & \\
\hline & $\checkmark \quad$ Urban & 136 & 17.0 \\
\hline & $\checkmark \quad$ Rural & 665 & 83.0 \\
\hline \multirow[t]{3}{*}{5.} & Education & & \\
\hline & $\checkmark \quad$ Primary or below & 534 & 66.7 \\
\hline & $\checkmark \quad$ Secondary or above & 267 & 33.3 \\
\hline
\end{tabular}

Table 3.2:Distribution of general population of Nasarawa by sexual behaviours and other selected characteristics

\begin{tabular}{|c|c|c|c|c|}
\hline & & & $\mathbf{n}$ & $\%$ \\
\hline \multirow[t]{4}{*}{1.} & Age at first sex & & & \\
\hline & & $\geq 18 \mathrm{yrs}$ & 489 & 61.05 \\
\hline & $\checkmark$ & $16-17 \mathrm{yrs}$ & 124 & 15.48 \\
\hline & $\checkmark$ & $\leq 15 \mathrm{yrs}$ & 188 & 23.47 \\
\hline \multirow{4}{*}{2.} & Transactional sex & & & \\
\hline & $\checkmark$ & No sex last 12 months & 238 & 29.71 \\
\hline & $\checkmark$ & No & 512 & 63.92 \\
\hline & $\checkmark$ & Yes & 51 & 6.37 \\
\hline \multirow[t]{4}{*}{3.} & Had more than o & one sex partners & & \\
\hline & $\checkmark \quad$ No sex last & t 12 months & 242 & 30.21 \\
\hline & $\checkmark \quad$ No & & 370 & 46.19 \\
\hline & $\checkmark \quad$ Yes & & 189 & 23.60 \\
\hline \multirow[t]{3}{*}{4.} & Comprehensive 1 & knowledge of HIV & & \\
\hline & $\checkmark \quad \mathrm{Nc}$ & & 463 & 57.8 \\
\hline & $\checkmark \quad \mathrm{Yc}$ & & 338 & 42.2 \\
\hline \multirow[t]{3}{*}{5.} & Ever Done HIV ' & Test & & \\
\hline & $\checkmark \quad$ No & & 446 & 55.7 \\
\hline & $\checkmark \quad$ Yes & & 355 & 44.3 \\
\hline \multirow[t]{3}{*}{6.} & Regular alcohol & use & & \\
\hline & $\checkmark \mathrm{N}$ & & 78 & 9.7 \\
\hline & $\checkmark \quad \mathrm{Ye}$ & & 723 & 90.3 \\
\hline \multirow[t]{3}{*}{7.} & Substance Use & & & \\
\hline & $\checkmark \quad$ No & & 47 & 5.9 \\
\hline & $\checkmark \quad$ Yes & & 754 & 94.1 \\
\hline \multirow[t]{4}{*}{8.} & Self-risk percept & tion & & \\
\hline & $\checkmark \quad$ High & & 38 & 4.7 \\
\hline & $\checkmark \quad$ Low & & 682 & 85.1 \\
\hline & $\checkmark \quad$ Don't knov & & 81 & 10.1 \\
\hline
\end{tabular}




\subsection{Association between risky sexual behaviours and selected characteristics of respondents.}

Chi square test was used to determine the association between sexual behaviour and selected sociodemographic and other factors. (Table.3.3). There was a statistically significant association between sexual behaviour and age group. Among the respondents aged 15-24 years, 54\% had high risk sexual behaviours compared to $72.1 \%$ among those aged $25-64$ years $(\mathrm{P}<0.001)$. Respondents who were ever married were more likely to have had risky sexual behaviour $(73.5 \%)$ compared to those who were never married $(26.5 \%) \quad(\mathrm{P}<0.001)$. Rural dwellers were at higher risk of risky sexual behaviour compared to urban respondents, $67.8 \%$ versus $56.6 \%$ $(\mathrm{P}<0.001)$. Prevalence of high risk sexual behaviours was 60.7\% among Muslims, 70.3\% among Christians and 69.2\% among adherents of other beliefs. $(\mathrm{P}=0.18)$. Among respondents with high risk perception, $65.8 \%$ compared $65.9 \%$ among respondents with low risk perception. The difference was not statistically significant. ( $\mathrm{P}=986)$. However, persons with high risk perception were likely to have had risky behaviour. $(\mathrm{P}=0.010)$. Levels of education, substance and alcohol use were not significantly associated with risky sexual behaviour.

\subsection{Bivariable Logistic regression model of factors associated with risky sexual behaviour.}

Table 4.4 shows the crude odds ratio, P-value and 95\% confidence interval for the association of selected factors with sexual behaviour. Rural dwellers were 1.6 times more likely to have had risky sexual behaviours (95\% CI:1.109-2.352). Similarly, for gender OR was 0.5(95 \% CI: 0.390-0.712). Respondents who were never married were $67.2 \%$ less likely to have had risky sexual behaviour than those who were ever married (95\% CI: 0.239-0.451). Christian respondents were 1.5 times more likely than Muslims to engage in risky sexual behaviours (95\% CI: 1.139-2.059) while adherents of other beliefs were 1.4 times more likely to engage in risky behaviours (95\% CI: 0.441-4.827).

Other factors found to be associated with risky sexual behaviour included HIV testing, substance use and comprehensive knowledge of HIV. Respondents who have never done HIV test were $46.8 \%$ less likely to engage in risky sexual behaviours compared those who have done the test $(95 \%$ CI: 0.396-0.715) while those who don't use substance were
$58.1 \%$ less likely to engage in risky sexual behaviours (95\% CI: 0.209-0.923). Respondents who had comprehensive knowledge of HIV were 1.6 times more likely to engage in risky behaviours (95\% CI: 1.18-2.161). Level of education, regular alcohol use and self-perception of risk were not significantly associated with risky sexual behaviour.

Table 3.3 Association between risky sexual behaviors and selected Characterist among the general population, Nasarawa State Nigeria, 2014

\begin{tabular}{|c|c|c|c|c|c|c|c|}
\hline & \multirow[b]{3}{*}{ Variable } & \multicolumn{4}{|c|}{ Sex Behaviour } & \multirow[t]{3}{*}{ Chi Sq } & \multirow[t]{3}{*}{ P-value } \\
\hline & & \multicolumn{2}{|c|}{ High } & \multicolumn{2}{|l|}{ Low } & & \\
\hline & & $\mathbf{n}$ & $\%$ & $\mathbf{n}$ & $\%$ & & \\
\hline \multirow[t]{3}{*}{1.} & Location & & & & & & \\
\hline & $\square$ Urban & 77.0 & 56.6 & 59.0 & 43.4 & 6.3064 & 0.012 \\
\hline & Rural & 451.0 & 67.8 & 214.0 & 32.2 & & \\
\hline \multirow[t]{3}{*}{2.} & Done HIV Test & & & & & & \\
\hline & $\square$ Yes & 322.0 & 72.2 & 124.0 & 27.8 & 17.6639 & $<0.001$ \\
\hline & $\square$ No & 206.0 & 58.0 & 149.0 & 42.0 & & \\
\hline \multirow[t]{3}{*}{3.} & Marital Status & & & & & & \\
\hline & $\square$ Ever Married & 416.0 & 73.5 & 150.0 & 26.5 & 49.3469 & $<0.001$ \\
\hline & Never Married & 112.0 & 47.7 & 123.0 & 52.3 & & \\
\hline \multirow[t]{7}{*}{4.} & Age group & & & & & & \\
\hline & $15-19$ & 47.0 & 38.5 & 75.0 & 61.5 & 54.41 & $<0.001$ \\
\hline & 19-24 & 101.0 & 66.5 & 51.0 & 33.6 & & \\
\hline & $25-29$ & 113.0 & 76.9 & 34.0 & 23.1 & & \\
\hline & 30-39 & 163.0 & 70.6 & 68.0 & 29.4 & & \\
\hline & $40-49$ & 64.0 & 65.3 & 34.0 & 34.7 & & \\
\hline & $\square 0-64$ & 40.0 & 78.4 & 11.0 & 21.6 & & \\
\hline \multirow[t]{3}{*}{5.} & Education & & & & & & \\
\hline & Primary and below & 343.0 & 64.2 & 191.0 & 35.8 & 2.0255 & 0.155 \\
\hline & Secondary and Above & 185.0 & 69.3 & 82.0 & 30.7 & & \\
\hline \multirow[t]{3}{*}{6.} & Alcohol use & & & & & & \\
\hline & $\square$ Yes & 55.0 & 70.5 & 23.0 & 29.5 & 0.8122 & 0.367 \\
\hline & $\square$ No & 473.0 & 65.4 & 250.0 & 34.6 & & \\
\hline \multirow[t]{3}{*}{7.} & Substance Use & & & & & & \\
\hline & $\square$ Yes & 22.0 & 46.8 & 25.0 & 53.2 & 2.1389 & 0.144 \\
\hline & $\square$ No & 435.0 & 57.7 & 319.0 & 42.3 & & \\
\hline \multirow[t]{3}{*}{8.} & $\begin{array}{l}\text { Comprehensive } \\
\text { Knowledge of HIV }\end{array}$ & & & & & & \\
\hline & $\square$ Yes & 243.0 & 71.9 & 95.0 & 28.1 & 9.2948 & 0.002 \\
\hline & $\square$ No & 285.0 & 61.6 & 178.0 & 38.4 & & \\
\hline \multirow[t]{3}{*}{9.} & Self-Risk Perception & & & & & & \\
\hline & $\square$ High & 25.0 & 54.0 & 126.0 & 46.0 & 0.0003 & 0.986 \\
\hline & $\square$ Low & 380.0 & 72.1 & 147.0 & 27.9 & & \\
\hline
\end{tabular}


Table 3.4 : Result of bivariable logistic regression model on factors associated with risky sexual behaviours among the general population in Nasarawa state, Nigeria 2014

\begin{tabular}{|c|c|c|c|c|c|}
\hline SNFactor & & Crude Odds Ratio & P-value & $95 \% \mathrm{C}$ & Interval \\
\hline 1. Gender & & & & & \\
\hline$\checkmark$ & Male & Ref & & & \\
\hline$\checkmark$ & Female & 0.5 & $<0.001$ & 0.390 & 0.712 \\
\hline 2. Marital s & atus & & & & \\
\hline$\checkmark$ & Ever married & Ref & & & \\
\hline$\checkmark$ & Never Married & 0.32 & $<0.001$ & 0.239 & 0.451 \\
\hline 3. Location & & & & & \\
\hline$\checkmark$ & Urban & Ref & & & \\
\hline$\checkmark$ & Rural & 1.6 & 0.013 & 1.109 & 2.352 \\
\hline 4. Educatio & & & & & \\
\hline$\checkmark$ & Primary and below & Ref & & & \\
\hline$\checkmark$ & Secondary and above & 1.3 & 0.155 & 0.917 & 1.721 \\
\hline 5. Age grou & & & & & \\
\hline$\checkmark$ & $15-19$ & Ref & & & \\
\hline$\checkmark$ & $20-24$ & 3.2 & $<0.001$ & 1.924 & 5.191 \\
\hline$\checkmark$ & $25-29$ & 5.3 & $<0.001$ & 3.125 & 9.002 \\
\hline$\checkmark$ & $30-39$ & 3.8 & $<0.001$ & 2.411 & 6.069 \\
\hline$\checkmark$ & $40-49$ & 3.0 & $<0.001$ & 1.728 & 5.223 \\
\hline$\checkmark$ & $50-64$ & 5.8 & $<0.001$ & 2.713 & 12.412 \\
\hline 6. Religion & & & & & \\
\hline$\checkmark$ & Other beliefs & Ref & & & \\
\hline$\checkmark$ & Christianity & 1.5 & 0.005 & 1.139 & 2.059 \\
\hline 7. Ever Dor & HIV Test & Ref & & & \\
\hline$\checkmark$ & Yes & & & & \\
\hline$\checkmark$ & No & 0.5 & $<0.001$ & 0.396 & 0.715 \\
\hline
\end{tabular}

8. Use substance

$\begin{array}{lll}\checkmark & \text { Yes } & \text { Ref } \\ \checkmark & \text { No } & 0.4\end{array}$

$0.030 \quad 0.2098$

0.923

9. Comprehensive HIV knowledge

$\begin{array}{ll}\checkmark & \text { No } \\ \checkmark & \text { Yes }\end{array}$

1.6

$0.002 \quad 1.180$

2.161

\subsection{Multivariable logistic regression model of factors associated with risky sexual behaviour among respondents.}

The following variables were included in the multivariable logistic regression: gender, location, marital status, religion, ever done HIV test, comprehensive knowledge of HIV, substance use and age. Table 3.6 shows that the odds ratio $(\mathrm{OR})$ for never married reduced slightly from $0.32(0.0 .239$ $0.451)$ to 0.26 (0.163-0.419), while rural resident reduced from 1.61 (1.109 -2.352 , significant) to 1.20 (0.775 to 1.871 , nonsignificant). The adjusted OR for the association between gender and risky sexual behaviour was 0.63 (95\% CI: 0.4360.915) while that for religion was Christianity versus other religious beliefs 1.549 (95\% CI: 1.078-2.047). Respondents with comprehensive knowledge of HIV were 1.49 times more likely to engage in risky sexual behaviour (95\% CI: 1.0562.108). Using the age group $15-19$ as the baseline, there was a significantly more likelihood to engage in risky sexual behaviours by respondents aged 20-24 (OR: 1.93; 95\% CI: 1.113-3.360) and 25-29 years (OR: 2.34; 95\% CI: 1.2674.308). Respondent aged 30-39 years, 40-49 and 50-64 years do not have significantly different sexual behaviours compared to the baseline. The multivariable regression analysis did not show any significant association between the primary outcome risky sexual behaviour and location, and previous HIV test. (Table 3.5)

Table 3.5: Result of multivariate logistic regression model on factors associated $\mathrm{w}$ risky sexual behaviours among the general population in Nasarawa state, Nigeria 2014

\begin{tabular}{|c|c|c|c|c|c|}
\hline \multicolumn{2}{|l|}{ SNFactor } & $\begin{array}{l}\text { Adjusted } \\
\text { Odds Ratio } \\
\end{array}$ & \multirow[t]{2}{*}{ P-value } & \multicolumn{2}{|c|}{ 95\% Conf. Interval } \\
\hline \multicolumn{5}{|l|}{ 1. Gender } & \\
\hline$\checkmark$ & Male & Ref & & & \\
\hline$\checkmark$ & Female & 0.63 & 0.015 & 0.436 & 0.915 \\
\hline \multicolumn{6}{|c|}{ 2. Marital status } \\
\hline$\checkmark$ & Ever married & Ref & & & \\
\hline$\checkmark$ & Never Married & 0.26 & $<0.001$ & 0.163 & 0.419 \\
\hline \multicolumn{6}{|l|}{ 3. Location } \\
\hline$\checkmark$ & Urban & Ref & & & \\
\hline$\checkmark$ & Rural & 1.20 & 0.409 & 0.775 & 1.871 \\
\hline \multicolumn{6}{|c|}{ 4. Education } \\
\hline$\checkmark$ & Primary and below & Ref & & & \\
\hline$\checkmark$ & Secondary and above & 1.07 & 0.744 & 0.716 & 1.597 \\
\hline \multicolumn{6}{|c|}{ 5. Age group } \\
\hline$\checkmark$ & $15-19$ & Ref & & & \\
\hline$\checkmark$ & $20-24$ & 1.93 & 0.019 & 1.113 & 3.360 \\
\hline$\checkmark$ & $25-29$ & 2.34 & 0.007 & 1.267 & 4.308 \\
\hline$\checkmark$ & $30-39$ & 1.20 & 0.550 & 0.658 & 2.196 \\
\hline$\checkmark$ & $40-49$ & 0.92 & 0.803 & 0.460 & 1.823 \\
\hline$\checkmark$ & $50-64$ & 1.29 & 0.595 & 0.508 & 3.259 \\
\hline \multicolumn{6}{|c|}{ 6. Religion } \\
\hline$\checkmark$ & Other beliefs & Ref & & & \\
\hline$\checkmark$ & Christianity & 1.49 & 0.015 & 1.078 & 2.047 \\
\hline \multicolumn{2}{|c|}{ 7. Ever Done HIV Test } & Ref & & & \\
\hline$\checkmark$ & Yes & & & & \\
\hline$\checkmark$ & No & 0.80 & 0.194 & 0.567 & 1.122 \\
\hline \multicolumn{6}{|c|}{ 8. Use substance } \\
\hline$\checkmark$ & Yes & Ref & & & \\
\hline$\checkmark$ & No & 0.45 & 0.054 & 0.202175 & 1.014 \\
\hline \multicolumn{6}{|c|}{ 9. Comprehensive HIV knowledge } \\
\hline$\checkmark$ & No & Ref & & & \\
\hline$\checkmark$ & Yes & 1.49 & 0.023 & 1.056 & 2.108 \\
\hline
\end{tabular}

\section{DISCUSSION}

The study showed that a significant proportion of the respondents engage in risky sexual behavior which is consistent with previous studies conducted in developing countries. ${ }^{11-17}$. However most of the previous studies were concentrated on young persons. High level of risky sexual behaviour among the 
general population is of great public health concern because of its effect on transmission of HIV and other sexually transmitted infections and unwanted pregnancies. In addition, unprotected sex and other risky sexual practices have long term consequences including other sexually transmitted infections such as syphilis and hepatitis B, cancers associated with sexual exposures such as cervical cancer. Among young persons, complications from illegal abortions are also of great concern to public Health experts and the government.

This study has shown that the following factors are associated with risky sexual behaviours: ever married, rural resident, male sex, comprehensive knowledge of HIV, substance use and age group 20-29 years. The finding on effect of gender on risky behaviour is not surprising. Females have been found to be generally less likely to engage in likely sexual behaviours. They are less likely to engage in accidental sex and have tendency to have unprotected sex only in stable, long term relationships. ${ }^{18,19}$ While men are more easily attracted to physical appearance, women generally enter into relationship based on affection.

In many African settings, the society is more tolerant of male engaging in unacceptable sexual practices than they do for females. The disparity in reported risky sexual behavior between males and females could also be due to reporting bias because females are less likely to report risky sexual behaviours. Because majority of the respondents are married, risky behaviours among males implies that the actual risk would be shared among the couples. This is in line with findings from the analyses of new HIV infections in Nasarawa State Nigeria which revealed that close to half of all new HIV infections in the state occur among persons who reported low risk including married partners. ${ }^{6}$ The male partners often serve as the bridge between the traditional high risk populations such as sex workers, MSM and injecting drug users and the general population.

Our finding on the effect of location of respondents on sexual behaviour is consistent with some of the previous studies. In a previous study carried out among young adults in Nigeria, rural residents were significantly more likely than their urban counterparts to have multiple sexual partners. ${ }^{20}$

However, some previous studies showed that persons residing in urban areas were more likely to have multiple sexual partner early sexual debut among other risky sexual behaviours. ${ }^{11,12}$ Rural residents have less access to information on HIV and AIDS as well as other sexually transmitted infections. In addition, the level of socio economic status especially income level is generally lower in the rural areas.

Regular alcohol, previous HIV test and self-risk perception were not significantly associated with risky sexual behaviour. Many of these findings are consistent with previous findings. Many studies have shown that both alcohol and substance use are associated with risky sexual behaviours. ${ }^{11,12,21-22}$ The data we analysed did not obtain information on quantity of alcohol used but rather on the frequency of use. While frequency of alcohol ingestion is important, combining it with quantity would have provided a better estimation of alcohol use.

One important finding in this analysis is that even through risky sexual behaviour was high (65.9\%), only $4.7 \%$ of the sampled population considered themselves to be at high risk of HIV. Previous studies have shown very varying findings on the association between personal risk perception and risky sexual behaviours. $^{23,24}$ Individuals who engage in risky sexual practices but yet have low personal risk perception are usually less likely to alter such practices. Research has shown that risk perception have been found to be more important in altering risky behaviours than level of knowledge of HIV transmission. ${ }^{27}$ The motivation to reduce the risky behaviours among these respondents is therefore expectedly very low and would need to be taken into consideration by HIV and AIDS control programmers and policy makers.

One major strength of this study is that it was conducted among the general population and thus would enable us apply the findings across the board. This has become imperative because the burden of HIV in Nasarawa state Nigeria is high and population based interventions are required to reduce this burden. Many previous studies in the state and elsewhere only looked at key population such as the sex workers, persons who inject drugs and men who have sex with men (MSM). A limitation of this study is the reporting and recall bias. The study relied on recall of exposures and the outcomes. Some respondents may not be able to recall some of their past practices with precision.

\section{CONCLUSION}

Close to two third of the respondents engaged in risky sexual behaviours (65.9\%) but only $4.7 \%$ considered themselves to be at high risk of HIV. The multivariable regression analysis showed that been married, rural resident, male sex, age between 20-29 years, use of substance and surprisingly 
knowledge of HIV were associated with risky sexual behaviour.

\section{RECOMIMENDATIONS}

There is need to urgently intensify media campaigns, community based interventions including one on one communications to reduce risky sexual behaviours among the general population. Further studies should be carried out on cultural factors inhibiting positive change in sexual behaviours despite existing interventions.

\section{REFERENCES}

1. Oster E. Sexually Transmitted Infection, Sexual behavior and the HIV/AIDs epidemic. The Quarterly Journal of Economics, 2005;120(2): 467-515. https://doi.org/10.1093/qje/120.2.467

2. Patra S. Socio-cultural correlates and risky sexual behaviour influencing prevalence of HIV/AIDS and STIs in Uganda: A gender perspective. Cogent Social Sciences, 2016; 2 (1): 1166472

3. Uchidi J, Magadi M and Mostaris MA. Multilevel analysis of the determinants of high risk sexual behavior (multiple sexual partners in sub-Saharan Africa social research methodology centre working paper (SRMC 2010/13). July 2010.

4. Akwasa PA, Madise NJ and Hinde A. perception of risk of HIV/AIDS and sexual behavior in Kenyan. Journal of Biosocial Science. 2003;35:385-411.

5. Kyeremeh, C. Risky Sex: How Cultural Norms Regarding Sexuality Inhibit Condom Use Among Kenyan Youth, 2009. Electronic Theses and Dissertations. University of Windsor, Canada, Paper 51. https://scholar.uwindsor.ca/etd/51

6. Bako IA, 1, Salihu A, Okekearu I and Anyanti J. Modeling of HIV Transmission in Nasarawa State, Nigeria: An Analysis of Distribution of New Infections. Journal of USChina Medical Science2017, 14: 116-122 doi:

10.17265/1548-6648/2017.03.003

7. Eze JI. Modelling HIV/AIDS Epidemic in Nigeria. A PhD Thesis, 2009, University of Glasgow. http://theses.gla.ac.uk/642/1/2009EzePhD.pdf, Accessed 1st September, 2016
8. UNAIDS. New HIV Infections by mode of transmission in West Africa: A Multi-Country Analysis. UNAIDS Regional Support Team for West and Central Africa, Senegal. A publication of Joint United Nations Programme on HIVIAIDS (UNAIDS) 2006 available at:

http://files.unaids.org/en/media/unaids/contentassets/docu ments/countryreport/2010/201003 MOT West Africa en. pdf. Accessed $1{ }^{\text {st }}$ September, 2016

9. Grassly NC, Garnett GP, Schwartl ̈nder B, Gregson S, Roy M. and Anderson RM. The effectiveness of HIV prevention and the epidemiological context. Bulletin of the World Health Organization, 2001;79: 1121-1132.

10. Merson MH, Dayton JM, O'Reilly K. Effectiveness of HIV prevention interventions in developing countries. AIDS. 2000;14Suppl 2:S68-84.

11. Yifu Berhan and Ares Berhan. A meta analysis of risky sexual behaviour among male youths in Developing Countries. AIDS Research and Treatment, Volume 2015, Article ID 580961, 9 pages. http://dx.doi.org/10.1155/2015/580961/. Accessed 1st September, 2016

12. Elissa M. Barr, Michele J. Moore. Safer Sex Day: A Program to Reduce Risky Sexual Behaviors. American International Journal of Social Science 2014;3( 4):1-12

13. Ahmadian M, Hanina H. Hamsan, H, Abdullah A, Snarulkhadi AS and Amna MN. Risky Sexual Behavior among Rural Female Adolescents in Malaysia: A Limited Role of Protective Factors. Global journal of health science. 2014;6(3):165-174

14. Brian AJI, Umeononihu O, Echendu AD and Eke N. Sexual Behaviour among Students in a Tertiary Educational Institution in Southeast Nigeria. Advances in Reproductive Sciences. 2016; 4:87-92.

15. Chen L, Jha P, Stirling B, Sgaier SK, Daid T, Sexual Risk Factors for HIV Infection in Early and Advanced HIV Epidemics in Sub-Saharan Africa: Systematic Overview of 68 Epidemiological Studies. PLoS ONE. 2007; 2(10) e1001: 1-14. doi:10.1371/journal.pone.0001001 (www.plosone.org).

16. Balwin P, Shrestha R, Potrepka J, and Copenhaves M. The Age of Initiation of Drug Use and Sexual Behaviors May Influence Subsequent HIV Risk Behaviors: A Systematic Review. International Scholarly Research Notices AIDS, 2013 Article ID 976035, 1-17. Accessed April 4, 2017, 
fromhttps://journals.plos.org/plosone/article?id=10.1371/jo urnal.pone.0001001.

17. Sikira A EP and Mamuya EP. Risk Behavior and HIV/AIDS Spread Among Petty Traders in Namanga Border (Tanzania And Kenya Border). International Journal of Asian Social Science, 2016;6(7): 418-429.

18. Puja Seth, Delia L Lang, Ralph J DiClemente, Nikia D Braxton, Richard A Crosby, Larry K Brown, Wendy Hadley and Geri R Donenberg. Gender differences in sexual risk behaviours and sexually transmissible infections among adolescents in mental health treatment. Sex Health, 2012; 9(3): 240-246.

19. Jadack RA, Hyde JS, Keller ML. Gender and knowledge about HIV, risky sexual behavior, and safer sex practices. Res Nurs Health. 1995 ;18(4):313-24.

20. Morenike Oluwatoyin Folayan, Sylvia Adebanjo, Adebayo Adeyemi, Kayode Michael Ogungbemi. Differences in sexual practices, sexual behaviours and HIV risk profile between adolescent and young persons in rural and urban Nigeria. Plos ONE, 2015. DOI:10.1371/journal.pone.0129106.

21. Atilola O1, Ayinde O, Adeitan O. Beyond prevalence and pattern: problematic extent of alcohol and substance use among adolescents in Ibadan South-west Nigeria. African Health Sciences 2013; 13(3): 777 - 784.
22. Gitonga M, Sinyard M, Gachuiri G. Alcohol and substance use vis a vis HIV Sexual Risk Behaviours among freshman students at a Kenyan University College; Focus for interventions. Journal of Biology, Agriculture and Healthcare. 2012;2(8):8-12.

23. Weiser SD, Leiter K, Heisler M, McFarland W, Percy-de Korte F. A population-based study on alcohol and high-risk sexual behaviors in Botswana.PLoS Med, 2006; 3(10): e392. DOI: 10.1371/journal.pmed.0030392. Accessed on $1^{\text {st }}$ September, 2017 from www.plosmedicine.org.

24. Shobo Y. Youth's perceptions of HIV infection risk: a sexspecific test of two risk models, African Journal of AIDS Research, 2007;6 (1): 1-8, DOI: $10.2989 / 16085900709490393$.

25. Johnston LD, O'Malley PM., Bachman JG, Schulenberg J E, Patrick ME, Miech RA. HIV/AIDS: Risk \& protective behaviors among adults ages 21 to 40 in the U.S., 20042017. 2018, Ann Arbor: Institute for Social Research, The University of Michigan. Accessed $1^{\text {st }}$ September 2017 at http://hdl.handle.net/2027.42/146526.

26. Catania JA, Kegeles SM and Coates TJ. Towards an understanding of Risk Behaviour: An AIDS Risk Reduction Model (ARRM). Health Education Quarterly, Spring 1990;17(1): 53-73. 